\title{
GPR43 mediates microbiota metabolite SCFA regulation of antimicrobial peptide expression in intestinal epithelial cells via activation of mTOR and STAT3
}

Ye Zhao ${ }^{1,2,9}$, Feidi Chen ${ }^{3,9}$, Wei Wu ${ }^{2,4}$, Mingming Sun ${ }^{2,4}$, Anthony J Bilotta ${ }^{2}$, Suxia Yao ${ }^{2}$, Yi Xiao ${ }^{2,5}$, Xiangsheng Huang ${ }^{2}$, Tonyia D Eaves-Pyles ${ }^{2}$, George Golovko ${ }^{6}$, Yuriy Fofanov ${ }^{6}$, Warren D’Souza ${ }^{7}$, Qihong Zhao ${ }^{8}$, Zhanju Liu ${ }^{4}$ and Yingzi Cong ${ }^{2,3}$

The antimicrobial peptides (AMP) produced by intestinal epithelial cells (IEC) play crucial roles in the regulation of intestinal homeostasis by controlling microbiota. Gut microbiota has been shown to promote IEC expression of Reglll $\gamma$ and certain defensins. However, the mechanisms involved are still not completely understood. In this report, we found that IEC expression levels of RegIll $\gamma$ and $\beta$-defensins 1,3 , and 4 were lower in G protein-coupled receptor (GPR) $43^{-\prime-}$ mice compared to that of wild-type (WT) mice. Oral feeding with short-chain fatty acids (SCFA) promoted IEC production of Reglll $\gamma$ and defensins in mice. Furthermore, SCFA induced Reglll $\gamma$ and $\beta$-defensins in intestinal epithelial enteroids generated from WT but not GPR43 ${ }^{-\prime-}$ mice. Mechanistically, SCFA activated mTOR and STAT3 in IEC, and knockdown of mTOR and STAT3 impaired SCFA induction of AMP production. Our studies thus demonstrated that microbiota metabolites SCFA promoted IEC Reglll $\gamma$ and $\beta$-defensins in a GPR43-dependent manner. The data thereby provide a novel pathway by which microbiota regulates IEC expression of AMP and intestinal homeostasis.

\section{INTRODUCTION}

In spite of being home to a diverse community of large numbers of indigenous microorganisms, host intestines live in harmony with microbiota under homeostatic conditions. Among multiple mechanisms involved in the regulation of host responses to microbiota in maintaining intestinal homeostasis, antimicrobial peptides (AMP) that are produced by intestinal epithelial cells (IEC) and Paneth cells serve as the first line of defense against microbiota and occasionally pathogens. ${ }^{1,2}$ AMP regulate host responses to microbiota and are involved in the maintenance of intestinal homeostasis. Several distinct families of AMP have been identified including defensins, cathelicidins, and C-type lectins (such as the regenerating islet-derived protein (REG) family). AMP function to kill or inactivate microorganisms rapidly through different mechanisms. ${ }^{1,2}$ The spectrum of antimicrobial activity varies for each particular AMP. In general, defensins affect both Grampositive and Gram-negative bacteria and, in some cases, fungi, viruses, and protozoa. ${ }^{3} \operatorname{RegIII} \gamma$, on the other hand, is selective for Gram-positive bacteria. ${ }^{4}$ Mutually, gut microbiota may also differentially regulate AMP production. For example, although expression of $\alpha$-defensins is independent of gut microbiota, the expression of RegIII $\gamma$ is virtually absent in germ-free (GF) mice and increased upon re-colonization with gut microbiota. ${ }^{4,5}$

How microbiota promotes the expression of AMP remains unclear. In mice deficient in MyD88, an adapter molecule

${ }^{1}$ Department of Gastroenterology, The First Affiliated Hospital of Zhengzhou University, Zhengzhou, China. ${ }^{2}$ Department of Microbiology and Immunology, University of Texas Medical Branch, Galveston, TX, USA. ${ }^{3}$ Department of Pathology, University of Texas Medical Branch, Galveston, TX, USA. ${ }^{4}$ Department of Gastroenterology, The Shanghai Tenth People's Hospital, Shanghai, China. ${ }^{5}$ Institute of Animal Nutrition, Sichuan Agricultural University, Ya'an, China. ${ }^{6}$ Department of Pharmacology and Toxicology, University of Texas Medical Branch, Galveston, TX, USA. ${ }^{7}$ Amgen Inc., South San Francisco, CA, USA and ${ }^{8}$ Bristol-Myers Squibb, Princeton, NJ, USA. Correspondence: Yingzi Cong (yicong@utmb.edu)

${ }^{9}$ These authors contributed equally to this work. 
common to most Toll-like receptors (TLRs), IEC expression levels of RegIII $\gamma$ and RegIII $\beta$ are decreased compared to that in wild-type (WT) mice, suggesting that IEC can directly sense bacteria through TLRs and promote the expression of RegIII $\gamma$ and RegIII $\beta .^{6,7}$ In addition, innate lymphoid cell (ILC) production of IL-22 has also been shown to promote IEC expression of RegIII $\gamma$ messenger RNA (mRNA). Notably, microbiota drives IL-22 production in ILCs, as demonstrated by the low levels of IL-22 produced by ILCs from GF mice. ${ }^{8}$ Thus, gut microbiota can regulate AMP expression, at least partially, through interaction with IEC TLRs or stimulating ILC IL-22 production.

Accumulating evidence indicates that the host immune system can sense gut bacterial metabolites in addition to TLR ligands. Recognition of these small molecules greatly impacts the host immune response. ${ }^{9,10}$ Among gut microbiota metabolites, shortchain fatty acids (SCFA), which are solely metabolized from indigestible carbohydrates by intestinal bacteria, ${ }^{11}$ have been shown to have immense impact on the host. ${ }^{12}$ Intact production of SCFA is associated with a reduced risk of different diseases, including inflammatory bowel diseases (IBD). As the most abundant SCFA, acetate, propionate, and butyrate are present in the colonic lumen of humans at high concentrations, ranging from 50 to 150 mm. ${ }^{11,13}$ SCFA can function through the activation of mammalian G protein-coupled receptors (GPCR). ${ }^{14}$ GPR41 and GPR43 are two major host receptors for most SCFA. ${ }^{15}$ SCFA can also inhibit histone deacetylase activity (HDAC) to downregulate macrophage pro-inflammatory cytokine production and activate peroxisome proliferator-activated receptor $\gamma$ to stimulate human colonic epithelial cell expression of angiopoietin-like protein 4 . $^{16,17}$ In addition, SCFA promote intestinal Treg cell development which is probably also mediated by their HDAC inhibitor activity but independent of GPR43, although it is still debatable as conflicting data have been published. ${ }^{10,18,19}$

SCFA butyrate has been demonstrated to induce LL-37/ hCAP18, a member of cathelicidin family, in various human colon cell lines. ${ }^{20}$ However, the underlying molecular mechanisms by which SCFA regulate IEC AMP production are still not completely understood. It has been reported that MAP kinases respond differently to butyrate stimulation. ${ }^{21}$ The MEK-ERK pathway regulates butyrate-induced LL-37 expression, whereas p38/MAP kinase exhibits little effect on AMP production. ${ }^{21,22}$ C-Jun N-terminal kinase (JNK) also positively regulates cathelicidin production in tissue epithelial cells. ${ }^{23}$ The current study was undertaken to investigate the mechanisms of AMP production induced by SCFA. Here, we report that SCFA promoted RegIII $\gamma$ and $\beta$-defensin expression in IEC through GPR43, which is mediated by mammalian target of rapamycin (mTOR) and signal transducers and activator of transcription 3 (STAT3).

\section{RESULTS}

\section{Expression of Reglll $\gamma$ and $\beta$-defensins in IEC is impaired in GPR43 $^{-I-}$ mice}

It has been previously reported that microbiota regulates IEC AMP expression differentially. ${ }^{4,5}$ As microbiota-derived SCFA can modulate IEC activity through GPR43, we investigated whether GPR43 regulates AMP expression in IEC. We
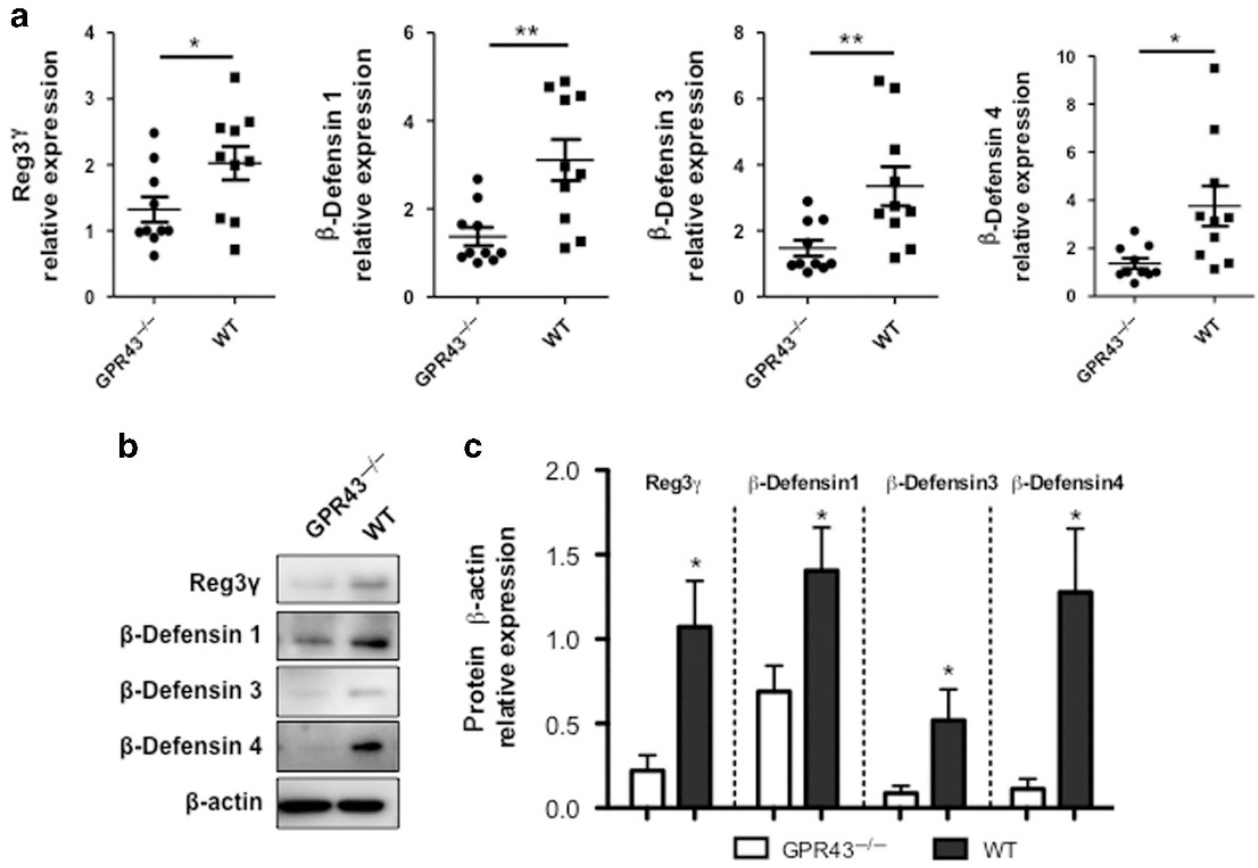

Figure 1 Decreased production of Reglll $\gamma$ and $\beta$-defensins in IEC of GPR43 ${ }^{-1-}$ mice. IEC from small intestine were isolated from WT and GPR43 ${ }^{-/-}$ mice respectively. (a) IEC expression of Reglll $\gamma$ and $\beta$-defensins 1,3 , and 4 in GPR43 ${ }^{-1}$ - and WT mice was determined by qRT-PCR and normalized against gapdh. Pooled data from two independent experiments. $n=5$ mice/group. (b) Protein levels of Reglll $\gamma$ and $\beta$-defensins were determined by western blot. Data are reflective of two independent experiments. $n=4$ mice/group. (c) Protein/ $\beta$-actin relative expression levels of Reglll $\gamma$ and $\beta$ defensins were compared between GPR43 ${ }^{-1-}$ and WT mice. Data were combined from two independent experiments. ${ }^{*} P<0.05$; ${ }^{* *} P<0.01$. IEC, intestinal epithelial cell; qRT-PCR, quantitative real-time polymerase chain reaction; WT, wild type. 
measured the expression of RegIII $\gamma$ and $\beta$-defensins 1,3 , and 4 in C57BL/6 (WT) and GPR43 ${ }^{-1-}$ mice at both RNA and protein levels. Quantitative real-time polymerase chain reaction (qRT-PCR) revealed that the transcription of RegIII $\gamma$ and $\beta$-defensin 1, 3, 4 mRNA was compromised in GPR $43^{-1-}$ IEC compared to the WT control (Figure 1a). Consistent with gene expression studies, protein levels of RegIII $\gamma$ and $\beta$-defensin 1, 3 , 4 in GPR $43^{-1-}$ mice were significantly lower compared to WT mice (Figure 1b,c). Collectively, these data indicated that SCFA recognition by GPR43 promotes IEC production of RegIII $\gamma$ and $\beta$-defensins.

\section{Feeding SCFA promotes IEC expression of RegIll $\gamma$ and $\beta$ - defensins in WT but not GPR43 ${ }^{-1-}$ mice}

As the most potent agonists for GPR43, SCFA play critical roles in intestinal barrier function. ${ }^{24,25}$ Butyrate, in particular, has been demonstrated to induce cathelicidin AMP and $\beta$-defensin 1 in human lung epithelial cells. ${ }^{23}$ We thus investigated whether SCFA can elicit a similar effect on IEC, and whether GPR43 mediates such effects. Because gut microbiota produces high levels of SCFA in the intestines which may confound the data interpretation, we first treated mice with broad-spectrum antibiotics for 10 days to eliminate gut microbiota as well as their metabolites SCFA, followed by 21 days of butyrate and antibiotics administration in drinking water. Intestinal epithelial cells were then isolated and assessed for AMP expression. We found decreased expression of RegIII $\gamma$, but no significant difference of $\beta$-defensins in mice receiving antibiotics compared to the control mice (Supplementary Figure S1 online). As expected, in WT mice, feeding butyrate enhanced the expression of RegIII $\gamma$ and $\beta$-defensin 1, 3, and 4 compared to controls in IEC (Figure 2a). Increased protein levels of RegIII $\gamma$ and $\beta$-defensins were also detected by western blot (Figure $\mathbf{2 b}, \mathbf{c}$ ). Feeding butyrate also increased expression of cathelicidin-related antimicrobial peptide (CRAMP) (Figure 2a). Additionally, mice fed with acetate slightly increased expression of RegIII $\gamma$ and $\beta$-defensins in IEC compared to control (Supplementary Figure S2). However, feeding butyrate did not affect the expression of RegIII $\gamma$ and $\beta$ defensin 1, 3, and 4 in IEC of GPR43 ${ }^{-1-}$ mice (Figure 2d). Together, these data suggested that SCFA serve as potent inducers of AMP production by IEC, which is mediated by GPR43.

We then investigated whether GPR43 and feeding butyrate affect gut microbiota, which could potentially mediate butyrate induction of AMP production. We fed WT and GPR43-1mice with $300 \mathrm{~mm}$ butyrate for 21 days, and gut microbiota assessed by $16 \mathrm{~s}$ ribosomal ribonucleic acid (rRNA) pyrosequencing of fecal samples. In GPR $43^{-1-}$ mice, the abundance of families of Prevotellaceae, Erysipelotrichaceae, and Alcaligenaceae was decreased compared to WT mice (Figure 3b). At genus level, Alistipes and Lactobacillus were increased while Alloprevotella, Blautia, and Odoribacter were decreased (Figure 3c), indicating that GPR43 signaling regulated gut microbiota composition. Feeding WT mice butyrate resulted in deviation of the microbial population toward an increased proportion of Bacteroidetes phylum (54.7-64.2\%, including Prevotellaceae, $P=0.06$ ) but decreased proportion of Proteobacteria phylum (7.3-4.0\%, including Helicobacteraceae and Alcaligenaceae, $P=0.05)$ and Firmicutes phylum (31.4-25.5\%, including Lachnospiraceae and Erysipelotrichaceae) (Figure 3a). However, in GPR $43^{-1-}$ mice, the increased proportion of Bacteroidetes phylum by feeding butyrate was decreased (from 51 to $55 \%$ ) compared with WT mice. Furthermore, butyrate did not affect proportion of Proteobacteria phylum in GPR43 ${ }^{-1-}$ mice. We also found that butyrate feeding increased the abundance of Prevotellaceae family but decreased the abundance of Alcaligenaceae family in WT mice but not in GPR $43^{-1-}$ mice (Figure 3b). At genus level, butyrate feeding increased abundance of Alloprevotella and Odoribacter but decreased abundance of Blautia and Lactobacillus in WT mice but not in GPR $43^{-1-}$ mice (Figure 3c). However, in contrast to the mice treated with antibiotics (Figure 2), feeding butyrate without depletion of gut bacteria did not increase IEC expression of RegIII $\gamma$ and $\beta$-defensins in both WT and $\mathrm{GPR}_{4} 3^{-/-}$mice (Supplementary Figure S3), possibly due to the high levels of pre-existing SCFA produced by gut microbiota in the intestines.

SCFA promote expression of Reglll $\gamma$ and $\beta$-defensins in both mouse and human IEC in vitro in a restricted time window

To determine whether SCFA directly promote the IEC expression of AMP in vitro, we utilized IEC lines and examined RegIII $\gamma$ and $\beta$-defensins expression after butyrate stimulation. We first used mouse small intestinal epithelial (MSIE) cells, a conditionally immortalized epithelial cell line that retains properties of primary IEC. ${ }^{26}$ We treated MSIE cells with butyrate for $48 \mathrm{~h}$ and measured RegIII $\gamma$ and $\beta$-defensins at both gene expression and protein levels. Treatment with butyrate significantly induced the expression of RegIII $\gamma$ and $\beta$-defensin 1,3 , and 4 (Figures $\mathbf{4 a}, \mathbf{b}$ ). We then determined the kinetics of the butyrate-induced IEC expression of RegIII $\gamma$ and $\beta$ defensins. We treated the MSIE cells with butyrate and measured RegIII $\gamma$ and $\beta$-defensins with respect to time over the course of $72 \mathrm{~h}$. Butyrate treatment did not induce expression of RegIII $\gamma$ and $\beta$-defensins in early time points of $1-12 \mathrm{~h}$. Their expression was slightly increased at $24 \mathrm{~h}$, but did not reach significance. Consistently, the expression levels of RegIII $\gamma$ and $\beta$-defensins were significantly increased at $48 \mathrm{~h}$, but returned to levels similar to those in controls by $72 \mathrm{~h}$ (Supplementary Figure S4), indicating that butyrate stimulation occurs within a narrow time window. Treatment with GPR43 agonist elicited similar effect on RegIII $\gamma$ and $\beta$-defensin 1, 3, and 4 expression (Figure 4c), indicating that GPR43 may mediate the butyrateinduced expression of RegIII $\gamma$ and $\beta$-defensins in IEC.

To investigate if SCFA also regulate expression of AMP in human IEC, a human colonic epithelial cell line (HT-29) was stimulated with $0.5 \mathrm{~mm}$ butyrate for $48 \mathrm{~h}$. Consistently, mRNA expression levels of RegIII $\alpha$, the human ortholog of mouse RegIII $\gamma, \beta$-defensin 1 , and LL-37 were enhanced in butyratetreated HT-29 cells (Figure 5a). However, butyrate did not 
a
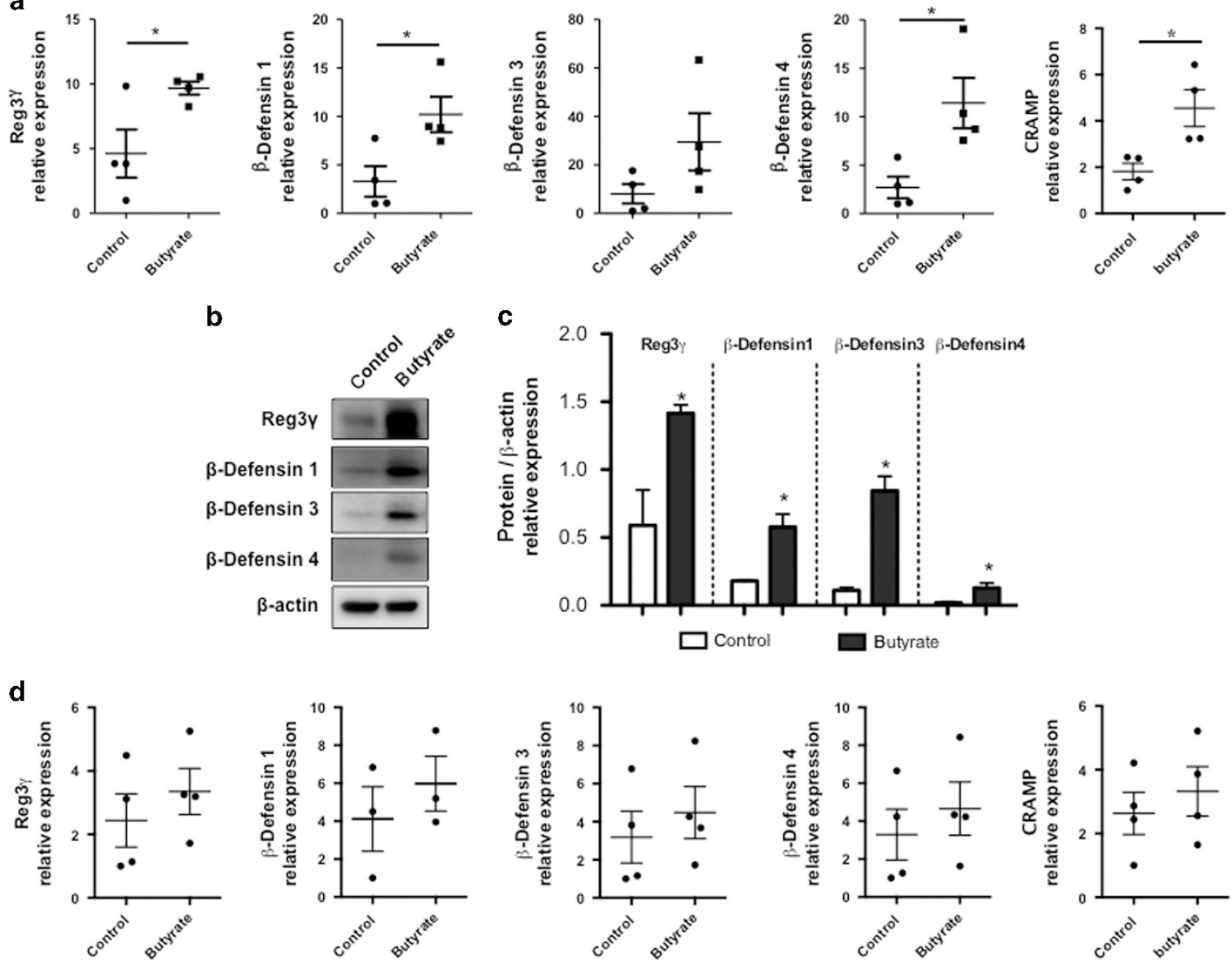

Figure 2 Butyrate feeding promotes IEC expression of Reglll $\gamma$ and $\beta$-defensins in vivo. WT and GPR43- ${ }^{-1}$ C57BL/6 mice were treated with antibiotics in drinking water for 10 days, and then fed with or without $300 \mathrm{~mm}$ butyrate in drinking water for 21 days. (a) IEC expression levels of Reglll $\gamma$, $\beta$-defensins 1 , 3 , and 4, and CRAMP in WT mice were determined by qRT-PCR and normalized against gapdh. Data are reflective of two independent experiments. $n=4$ mice/group. (b) Protein levels of Reglll $\gamma$ and $\beta$-defensins determined by western blot in WT mice. Data are reflective of two independent experiments. (c) Protein/ $\beta$-actin relative expression levels of Reglll $\gamma$ and $\beta$-defensins were compared between control and butyrate-treated WT mice. Data were combined from two independent experiments. ${ }^{*} P<0.05$. (d) IEC expression levels of Reglll $\gamma$ and $\beta$-defensins 1,3 , and 4 in GPR $43^{-1-}$ mice were determined by qRT-PCR and normalized against gapdh. Data are reflective of two independent experiments. $n=4$ mice/group. IEC, intestinal epithelial cell; qRT-PCR, quantitative real-time PCR; WT, wild type.

affect the expression of $\alpha$-defensin 5 and $\alpha$-defensin 6 in HT-29 cells (Figure 5a). We also demonstrated a similar effect of acetate and propionate on HT-29 cells. While propionate induced mRNA expression of both RegIII $\alpha$ and $\beta$-defensin 1, the expression of $\alpha$-defensins remained unaffected. Acetate induced $\beta$-defensin 1 but not RegIII $\alpha$ and $\alpha$-defensins (Supplementary Figure S5). Moreover, GPR43 agonist promoted HT-29 cell expression of RegIII $\alpha, \beta$-defensin 1, and LL-37 but not $\alpha$-defensin 5 and $\alpha$-defensin 6 (Figure $5 \mathbf{b}$ ).

SCFA induce expression of Reglll $\gamma$ and $\beta$-defensins in WT but not GRP43 ${ }^{-l-}$ small intestinal epithelial enteroids

We next sought to determine if IEC expression of GPR43 directly mediates SCFA-induced AMP production. We established an ex vivo three-dimensional enteroid culture to recapitulate the comprehensive intestinal microenvironment. Enteroids were generated from WT and GRP43 ${ }^{-1-}$ mice respectively, and treated with butyrate or PBS control for $48 \mathrm{~h}$. Butyrate treatment did not affect the viability of enteroids as well as the expression of Mki67 (gene for proliferation) and
Lgr5 (gene for stemness) (Supplementary Figure S6). As shown in Figure 6, butyrate treatment induced the expression of RegIII $\gamma$ and $\beta$-defensin 1 in WT enteroids, whereas the effect was abrogated in GPR43 ${ }^{-1-}$ organoids. These data confirmed that GPR43 mediates IEC production of RegIII $\gamma$ and $\beta$ defensins induced by butyrate.

\section{mTOR mediates SCFA induction of Reglll $\gamma$ and $\beta$-defensins in IEC}

The mTOR, an evolutionarily conserved integrative serinethreonine kinase, is a crucial regulator of physiology of various cells in response to environmental cues and nutrients. ${ }^{27} \mathrm{mTOR}$ functions through phosphorylating the eukaryotic initiation factor 4E-binding protein 1 (4E-BP1) and p70 ribosomal S6 kinase 1 (S6K1). SCFA have been shown to activate mTOR in T cells and dendritic cells (DC). ${ }^{13,28}$ We thus investigated whether the mTOR pathway is involved in SCFA-induced RegIII $\gamma$ and $\beta$-defensins production in IEC. We first treated MSIE cells with butyrate and measured mTOR activation by detecting both phosphorylated-mTOR (p-mTOR) and phosphorylated- 

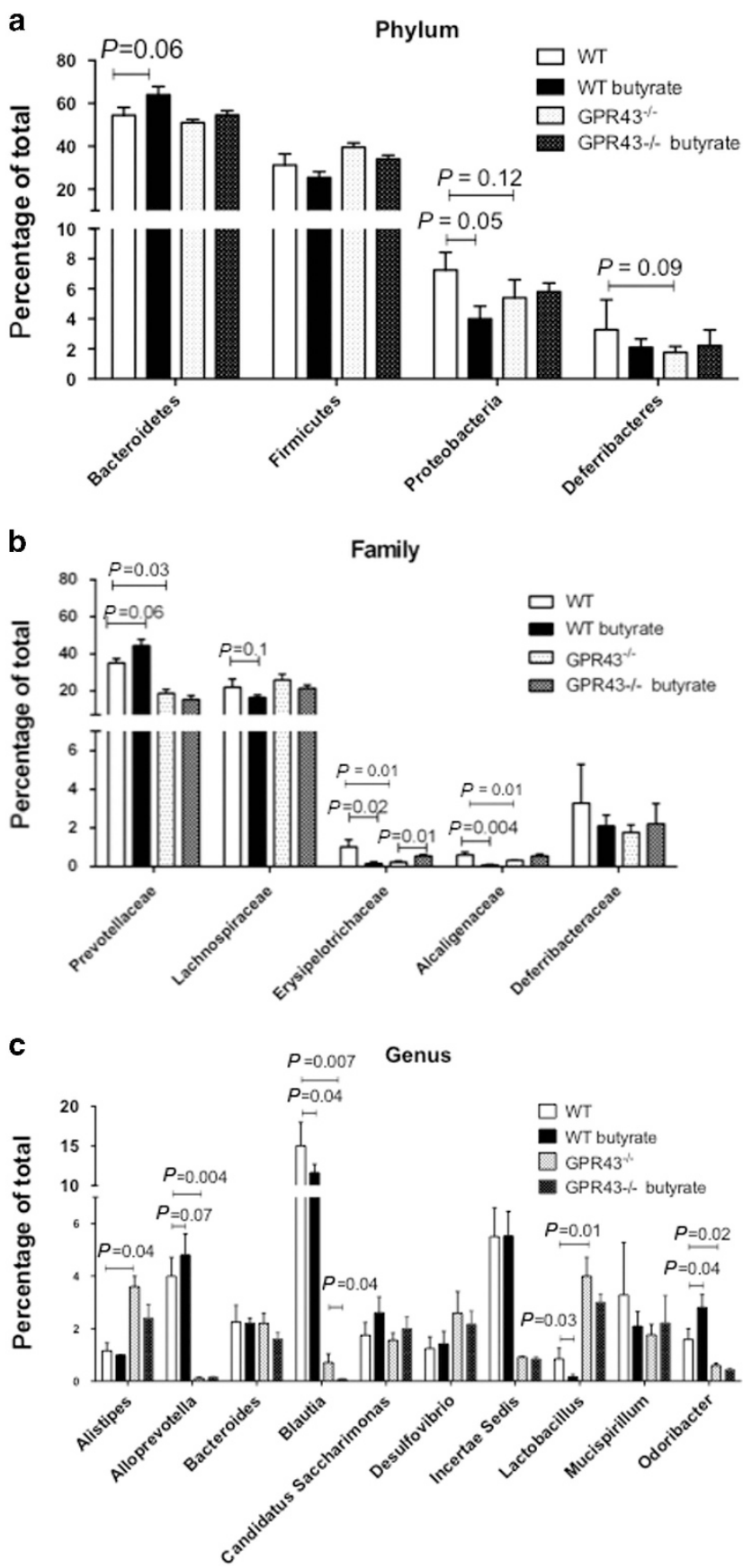

Figure 3 Butyrate feeding changes gut microbiota. WT and GPR $43^{-1-}$ C57BL/6 mice were fed with $300 \mathrm{~mm}$ butyrate for 21 days. Gut microbiota prior and after feeding butyrate was determined by $16 \mathrm{~s}$ rRNA sequencing. Bar charts for fecal bacterial composition of phylum level (a), family level (b), and genus level (c). $N=4-5$ mice/group. WT, wild type.

4EBP1 (p-4EBP1). As shown in Figure 7a, butyrate promoted the expression of $\mathrm{p}-\mathrm{mTOR}$ and $\mathrm{p}-4 \mathrm{EBP} 1$. Consistently, we detected activation of S6K1 by flow cytometry in butyratetreated MSIE cells (Figure 7b). Moreover, butyrate activation of mTOR signaling was via GPR43, as evidenced by the activation of mTOR downstream effector S6K1 by a GPR43 agonist (Supplementary Figure S7). To determine that butyrateinduced mTOR activation contributes to IEC production of
RegIII $\gamma$ and $\beta$-defensins, we used mTOR siRNA to specifically knockdown mTOR. MSIE cells were transfected with mTOR siRNA or control non-targeting siRNA, with a transfection efficiency around 50\% (Figure 7c). The cells were then treated with butyrate. Knockdown of mTOR impaired butyrateinduced expression of RegIII $\gamma$ and $\beta$-defensins at the levels of both mRNA (Figure 7d) and proteins (Figure 8e). Collectively, these data demonstrated that butyrate activates the mTOR pathway to positively regulate RegIII $\gamma$ and $\beta$ defensins production in IEC.

\section{STAT3 regulates butyrate promotion of Reglll $\gamma$ and $\beta$ - defensins production in IEC}

It has been shown that STAT3 is required for RegIII $\gamma$ production in lung epithelium. ${ }^{29}$ Likewise, it is also necessary for IL-22-induced RegIII $\gamma$ and $\beta$-defensins production in human IEC and alveolar epithelium. ${ }^{30-32}$ We postulated that STAT3 regulates SCFA induction of AMP production in IEC. Butyrate treatment led to activation of STAT3 in MSIE cells, evidenced by enhanced phosphorylation of STAT3 (Figure 8a). Blockade of STAT3 using a specific STAT3 inhibitor $\mathrm{HJC} 0152^{33}$ greatly attenuated butyrate-induced RegIII $\gamma$ and $\beta$-defensins mRNA expression (Figure $8 \mathbf{b}$ ). Secondly, we knocked down STAT3 in MSIE cells with specific siRNA. The obtained transfection efficiency was about $50 \%$ (Figure 8c). In accordance with the data of the STAT3 inhibitor, the knockdown of STAT3 resulted in decreased butyrate-induced IEC expression of RegIII $\gamma$ and $\beta$-defensins at the levels of both mRNA and proteins (Figure 8d,e). Together, these data indicated that STAT3 is critical for the butyrate-induced AMP production in IEC.

\section{DISCUSSION}

The interplay between gut commensal bacteria and the host provides beneficial effects on host metabolism as well as immune regulation. ${ }^{34-36}$ In this report, we have demonstrated that gut microbiota metabolites SCFA promoted IEC expression of RegIII $\gamma$ and $\beta$-defensins 1,3 , and 4 through GPR43, essential for the maintenance of intestinal homeostasis.

Gut microbiota has been shown to be important for the production of certain AMP in the intestines, in that RegIII $\gamma$ and certain $\beta$-defensins are virtually absent in GF mice. ${ }^{4,5}$ Mice lacking TLR ligands also displayed impaired production of RegIII $\gamma$ and RegIII $\beta$ in IEC compared to WT mice, suggesting that microbiota can directly affect IEC AMP production through interaction with TLRs. ${ }^{6,7}$ However, substantial amounts of AMP have been detected in MyD88 ${ }^{-1-}$ mice housed under specific pathogen free (SPF) conditions. ${ }^{4-7}$ This indicates the presence of multiple sensors and mechanisms for AMP regulation by microbiota, in addition to direct TLR-TLR ligand interactions. In the current report, we investigated whether SCFA regulated the IEC production of RegIII and the defensin family. Indeed, extraneous butyrate administration promoted IEC production of RegIII $\gamma, \beta$-defensin 1, 3, and 4, and CRAMP (Figure 2). This was further supported by in vitro 

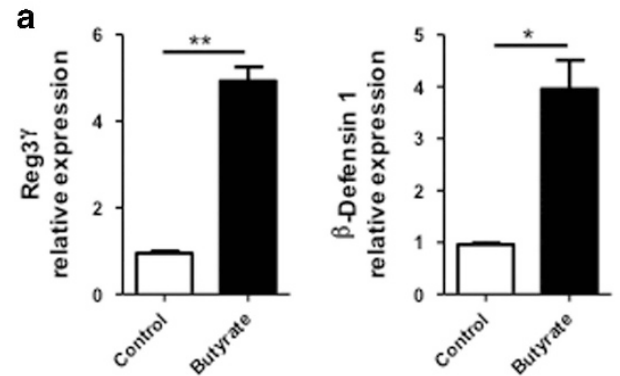

b
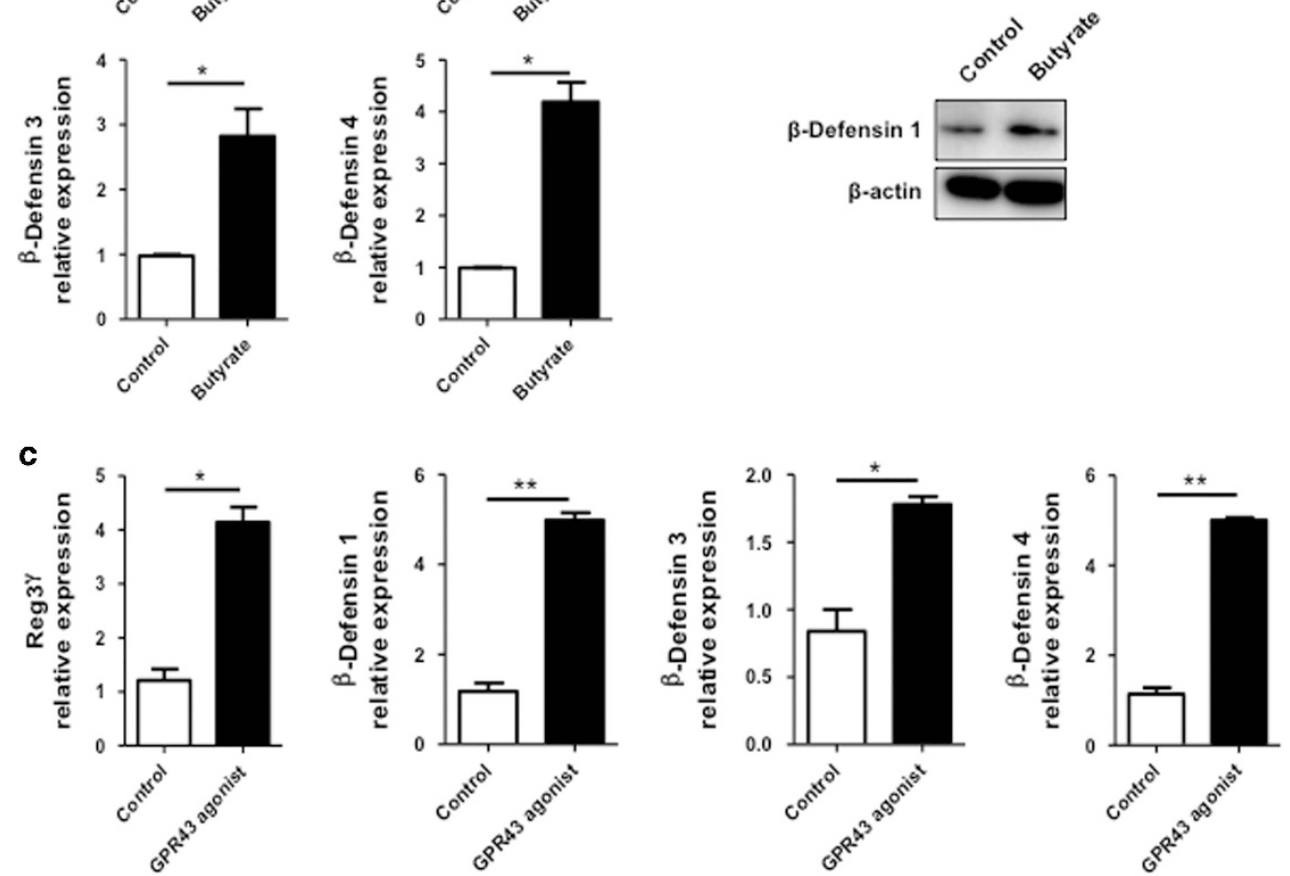

Figure 4 Butyrate and GPR43 agonist induce expression of Reglll $\gamma$ and $\beta$-defensins in mouse IEC. MSIE cells were treated with $0.5 \mathrm{~mm}$ butyrate for $48 \mathrm{~h}$. (a) The expression of Reglll $\gamma$ and $\beta$-defensins mRNA determined by qRT-PCR and normalized against gapdh. (b) Protein levels of Reglll $\gamma$ and $\beta$-defensin 1 determined by western blot. (c) MSIE cells were treated with $5 \mu \mathrm{m}$ GPR43 agonist. The expression levels of Reglll $\gamma$ and $\beta$-defensins were determined by qRT-PCR at $48 \mathrm{~h} .{ }^{*} P<0.05 ;{ }^{\star \star} P<0.01$. Data are reflective of three independent experiments. IEC, intestinal epithelial cell; mRNA, messenger RNA; MSIE, mouse small intestinal epithelial; qRT-PCR, quantitative real-time PCR.

studies using human and murine intestinal cell lines (Figures 4 and 5). Interestingly, a previous report showed that SCFA also promoted $\beta$-defensin expression in porcine IEC by using porcine IPEC-J2 IEC, ${ }^{37}$ indicating that SCFA can function across different species to promote IEC expression of AMP.

It has been shown that SCFA bind cell-surface receptors such as GPR41, GPR43, and GPR109 $\alpha^{13,38}$ SCFA-GPR43 interaction has been reported in regulating intestinal inflammatory responses, ${ }^{39}$ in that GPR43 ${ }^{-1-}$ mice demonstrated exacerbated colitis after dextran sodium sulfate insult. ${ }^{40}$ This further indicates that SCFA affects the intestine via the GPR43 receptor. More recently, it was discovered that low fiber diets induced and perpetuated intestinal inflammation, whereas high fiber diets protected against colitis. ${ }^{41}$ The beneficial effect of high fiber intake derives from gut microbiota metabolic products, and subsequent SCFA binding to GPR43 and GPR109a in the intestines. Further studies revealed that SCFA activated the NLRP3 inflammasome through GPCR signaling, which conferred resistance to colitis. ${ }^{41}$ Our data demonstrated that production of RegIII $\gamma$ and $\beta$-defensins in IEC was impaired in GPR $43^{-l-}$ mice (Figure 1). Additionally, administration of a GPR43 agonist enhanced AMP production in both murine and human IEC, indicating that GPR43 is involved in AMP production. Furthermore, butyrate promoted expression of RegIII $\gamma$ and $\beta$-defensins in WT but not in GPR $43^{-l-}$ intestinal epithelial enteroids (Figure 6). SCFA, especially butyrate, have been shown as HDAC inhibitors, and butyrate-induced HDAC3 inhibition regulates IEC production of retinoic acid, which can potentially contribute to maintenance of intestinal homeostasis. ${ }^{42}$ Our data do not rule out the involvement of HDAC inhibition in SCFA induction of AMP in IEC. It is very likely that SCFA regulate IEC function via multiple mechanisms.

mTOR is a key regulator in various physiological aspects. ${ }^{43}$ Among different cell types, SCFA have been shown to activate mTOR in T cells and DCs. ${ }^{27,44}$ We showed that SCFA activated the mTOR pathway in IEC (Figure 7a). Knockdown of mTOR attenuated SCFA-induced AMP production, indicating that activation of mTOR facilitated RegIII $\gamma$ and $\beta$-defensins production in IEC. Interestingly, butyrate also activated STAT3, which has been implicated in the regulation of immune responses of both innate and adaptive immune 

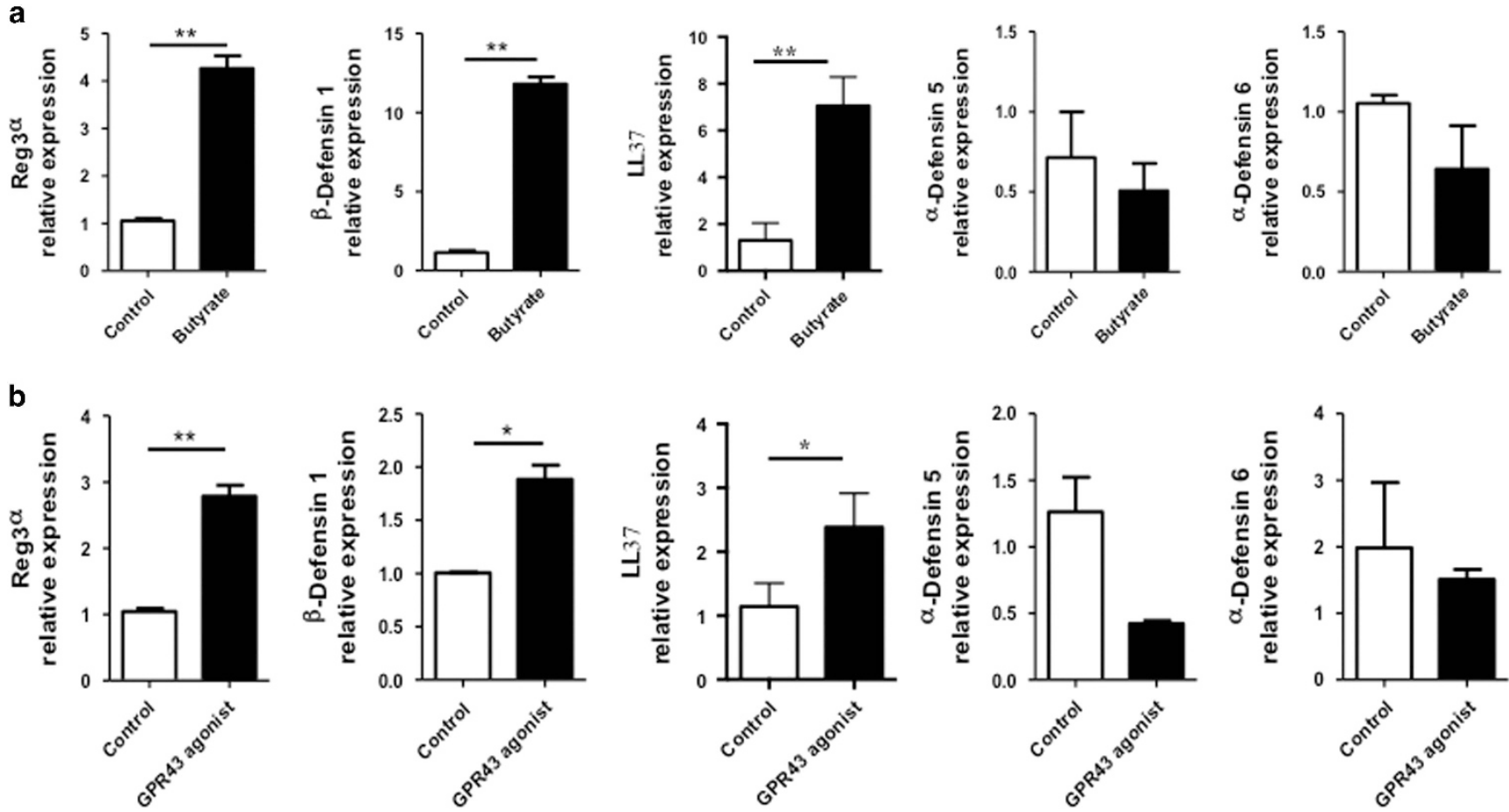

Figure 5 Butyrate and GPR43 agonist induce expression of Reglll $\gamma$ and $\beta$-defensins in human IEC. HT-29 cells were treated with $0.5 \mathrm{~mm}$ butyrate for $48 \mathrm{~h}$. (a) The expression levels of $\alpha$-defensins, $\beta$-defensins, Reglll $\alpha$, and LL37 were determined by qRT-PCR and normalized against gapdh. (b) HT-29 cells were treated with $5 \mu \mathrm{m}$ GPR43 agonist $48 \mathrm{~h}$, and the expression levels of $\alpha$-defensin $6, \beta$-defensin 1 , Reglll $\alpha$, and LL37 were determined by qRTPCR. ${ }^{*} P<0.05 ;{ }^{* *} P<0.01$. Data are reflective of three independent experiments. IEC, intestinal epithelial cell; qRT-PCR, quantitative real-time PCR.
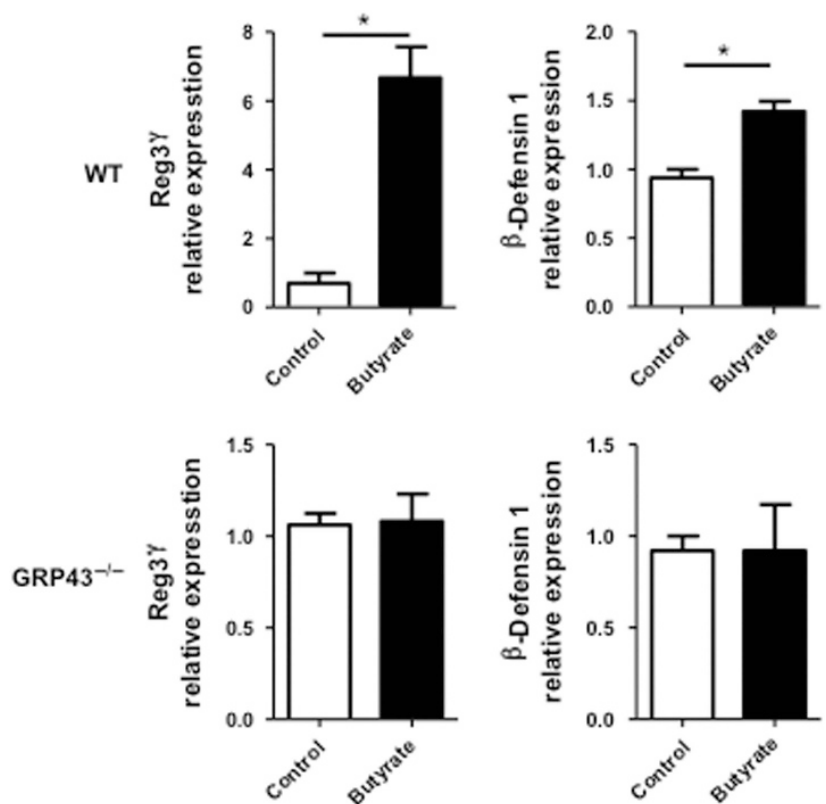

Figure 6 Butyrate induces expression of Reglll $\gamma$ and $\beta$-defensins in WT but not GPR $43^{-1-}$ intestinal epithelial enteroids. Intestinal epithelial enteroids were generated from either WT or GPR $43^{-1-}$ mice, and treated with $0.5 \mathrm{~mm}$ butyrate. The expression levels of Reglll $\gamma$ and $\beta$-defensins were determined by qRT-PCR at $48 \mathrm{~h}$ and normalized against gapdh. ${ }^{\star} P<0.05$. Data are reflective of two independent experiments. qRT-PCR, quantitative real-time PCR; WT, wild type.

cells in the intestines. ${ }^{45}$ The blockade of STAT3 signaling compromised RegIII $\gamma$ and $\beta$-defensins production in SCFAtreated IEC, suggesting that STAT3 is indispensable in SCFA induction of AMP production in IEC (Figure 8). As activation of STAT3 impacts epithelial cell viability, it is very likely that SCFA activation of STAT3 supports intestinal organoid stemness proliferation, which will affect the AMP secretion by an indirect mechanism as well. Therefore, SCFA activation of mTOR and STAT3 could collaboratively promote AMP expression in IEC.

RegIII $\gamma$ and $\beta$-defensins secreted by IEC are known for limiting bacteria and manipulating species composition, especially Grampositive species. Our findings that SCFA induce IEC RegIII $\gamma$ and $\beta$-defensins production in IEC suggest a possible autoregulation of microbiota. In light of this, drugs targeting the intrinsic pathways of SCFA-mediated AMP production might serve as promising candidates for clinical applications by promoting host barrier defense and correcting dysbiosis, and restoring homeostatic balance. Nevertheless, the modification of AMP requires carefully monitoring, and dysregulated AMP production can have negative impacts on intestinal homeostasis. Indeed, it was discovered that excessive lipocalin- 2 and calprotectin production induced by IL22 can, in turn, suppress commensal bacteria, resulting in pathogen colonization. ${ }^{46}$ In order to preserve intestinal homeostasis, critical elements of host immunity and microbial colonization need to counterbalance each other. To that end, we present evidence that metabolites from commensal microbiota are capable of inducing host innate immunity to regulate the intestinal environment.

Moreover, we demonstrated that GPR43 signaling regulated gut microbiota and feeding butyrate resulted in alterations in the composition of the microbiota (Figure 3). Among the 


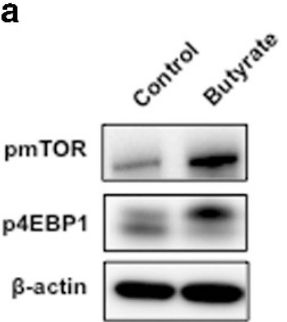

b

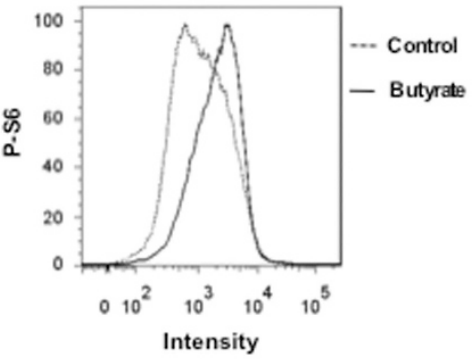

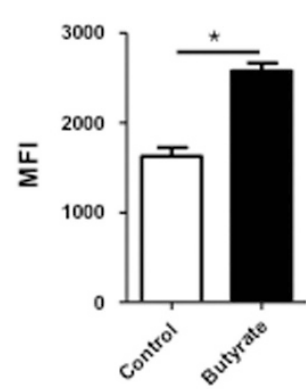

C

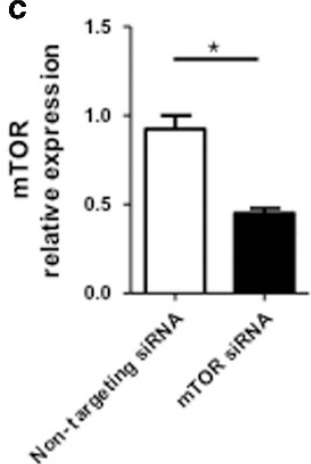

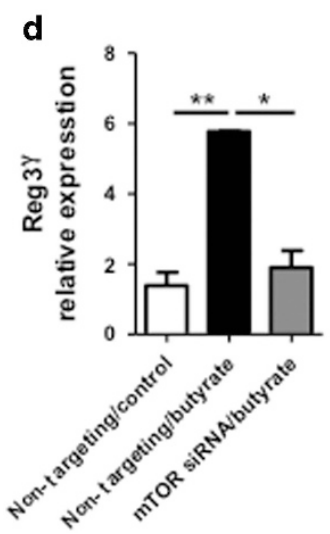
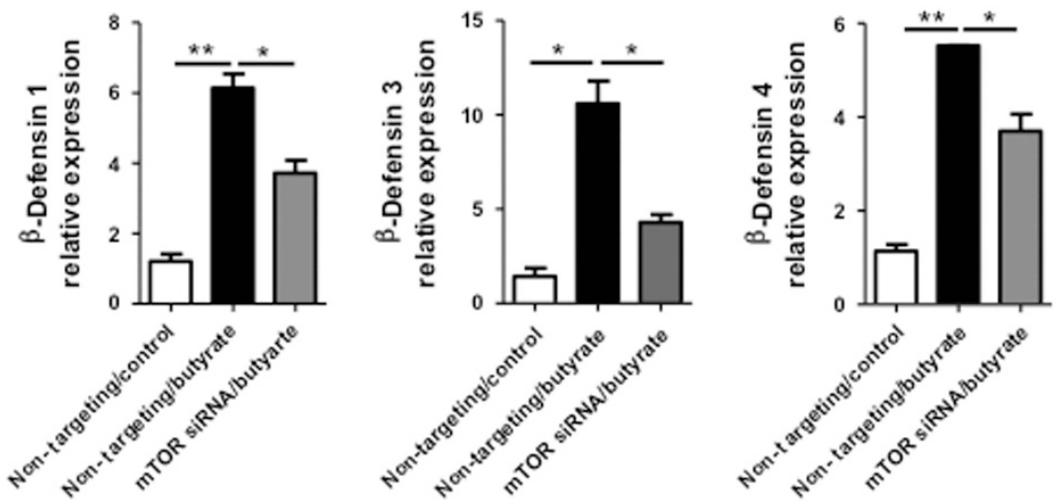

Figure 7 mTOR regulates butyrate induction of Reglll $\gamma$ and $\beta$-defensins in IEC. MSIE cells were treated with $0.5 \mathrm{~mm}$ butyrate for $1 \mathrm{~h}$. (a) Phosphorylation of $\mathrm{mTOR}$ and 4E-BP1 was determined by western blot with $\beta$-actin as a loading control. (b) The expression of phosphorylated S6K1 was determined by flow cytometry at $48 \mathrm{~h}$ post butyrate treatment. Combined MFI was presented. (c,d) MSIE cells were transfected with mTOR siRNA or control nontargeting siRNA, followed by $0.5 \mathrm{~mm}$ butyrate for $48 \mathrm{~h}$. (c) siRNA knockdown efficiency was confirmed by RT-PCR at $40 \mathrm{~h}$ post transfection. (d) The expression levels of Reglll $\gamma$ and $\beta$-defensins were determined by qRT-PCR and normalized against gapdh $48 \mathrm{~h}$ post treatment. ${ }^{*} P<0.05$; ${ }^{* \star} P<0.01$. Data are reflective of three independent experiments. IEC, intestinal epithelial cell; MFI, median fluorescence intensity; MSIE, mouse small intestinal epithelial; mTOR, mammalian target of rapamycin; qRT-PCR, quantitative real-time PCR.

bacteria affected by GPR43 signaling, the abundance of Prevotellaceae was decreased in GPR43 ${ }^{-1-}$ mice compared to WT mice. Feeding WT mice but not GPR43 ${ }^{-1-}$ mice butyrate increased the abundance of Prevotellaceae. A recent report by Jiminez et al. demonstrated more potent effects of butyrate on gut microbiota by rectal administration of $140 \mathrm{~mm}$ butyrate, especially when mice developed colitis upon infection with Citrobacter rodentium. ${ }^{47}$ The difference of the data between Jiminez et al. and our current study is likely due to the different routes of butyrate administration. While butyrate by rectal administration would mostly go to the colon, due to potential absorption, only a small portion of oral administered butyrate would reach the intestinal lumen to affect gut microbiota. Even so, in consistent with our results, their study also demonstrated an increased proportion of Bacteroidetes phylum but decreased Firmicutes phylum after rectal administration of butyrate. ${ }^{47}$ While our data demonstrated that butyrate promotes IEC AMP production, which can in turn affects microbiota composition, direct antimicrobial effects of butyrate have also been reported, ${ }^{48}$ both of which can contribute to butyrate-induced microbiota alterations. Whether these changes directly or indirectly affect butyrate regulation of IEC expression of AMP cannot be stated at this point; however, we showed that SCFA-producing phyla were altered by feeding butyrate. While the Bacteroidetes phylum, which produces mainly acetate and propionate, was increased, members of the Firmicutes phylum, which preferentially produce butyrate, ${ }^{49}$ were decreased. Thus, we are still not clear, at this point, whether and at what levels the butyratemediated alternations of gut microbiota contribute to butyrate induction of IEC AMP expression.

\section{METHODS}

Mice. C57BL/6 mice were purchased from the Jackson Laboratory and housed in the Animal Resource Center at University of Texas Medical Branch (UTMB). GPR43 $3^{-1-}\left(\right.$ Ffar2 $\left.{ }^{\text {tmlLex }}\right)$ mice were obtained from Bristol-Myers Squibb and maintained in the Animal Resource Center at UTMB. All experiments were reviewed and approved by the Institutional Animal Care and Use Committees of UTMB.

Reagents. OPTI-MEM were purchased from Life Technologies. GPR43 agonist (phenylacetamide agonist \#44, Amgen) ${ }^{50}$ was kindly provided by Dr Warren N. D’Souza, Amgen. STAT3 inhibitor HJC0152 was kindly provided by Dr Jia Zhou, University of Texas Medical Branch. McCoy's 5A and Lipofectamine RNAiMAX Transfection Reagent were purchased from Thermo Fisher Scientific. Sodium butyrate (MKBZ0227V), sodium propionate (SLBL9015V), and sodium acetate (SLBH4840V) were purchased from Sigma-Aldrich. Predesigned siRNA directed against mouse mTOR (SI01005683), STAT3 (SI01435287), and negative control siRNA (1027310) were purchased from Qiagen. Antibodies against phosphor-STAT3 (Tyr705), phosphor-mTOR (S2448), 

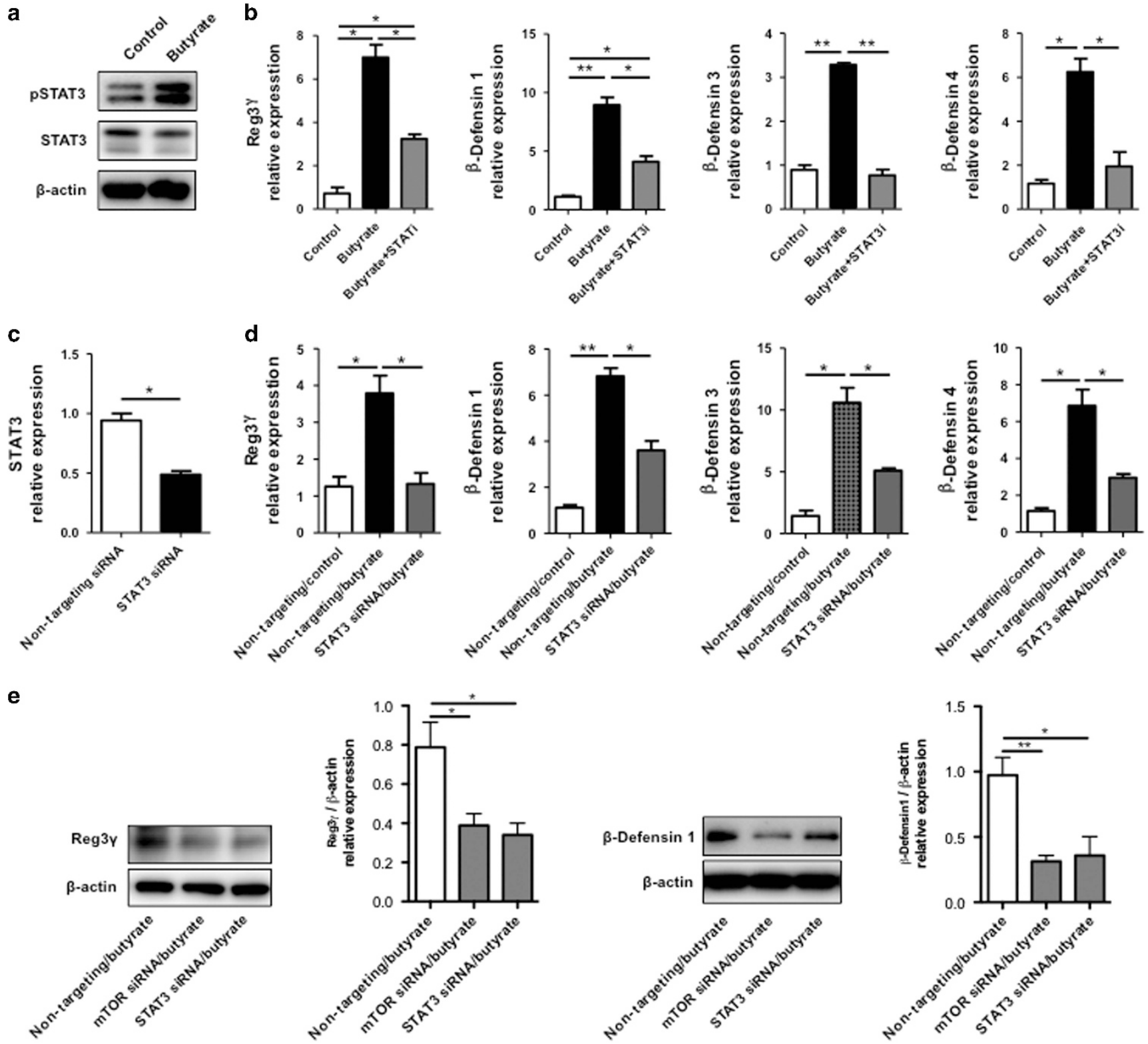

Figure 8 STAT3 regulates butyrate induction of Reglll $\gamma$ and $\beta$-defensin in IEC. MSIE cells were treated with $0.5 \mathrm{~mm}$ butyrate for $1 \mathrm{~h}$. (a) Phosphorylation of STAT3 was determined by western blot with total STAT3 and $\beta$-actin as loading controls. (b) MSIE cells were treated with $0.5 \mathrm{~mm}$ butyrate in the presence or absence of $5 \mu \mathrm{m}$ STAT3 inhibitor HJC0152. The expression levels of Reglll $\gamma$ and $\beta$-defensins were determined by qRT-PCR at $48 \mathrm{~h}$ and normalized against gapdh. (c,d) MSIE cells were transfected with STAT3 siRNA or control non-targeting siRNA and then treated with 0.5 mm butyrate. (c) siRNA knockdown efficiency was confirmed by RT-PCR at $40 \mathrm{~h}$ post transfection. (d) The expression levels of Reglll $\gamma$ and $\beta$-defensins were determined by qRT-PCR $48 \mathrm{~h}$ post transfection and normalized against gapdh. (e) Protein levels of Reglll $\gamma$ and $\beta$-defensin were determined by western blot and combined protein/ $\beta$-actin relative expression was presented. ${ }^{\star} P<0.05 ;{ }^{\star \star} P<0.01$. Data are reflective of three independent experiments. IEC, intestinal epithelial cell; MSIE, mouse small intestinal epithelial; qRT-PCR, quantitative real-time PCR; STAT3, signal transducers and activator of transcription 3.

phosphor-4E-BP1 (T70), phosphor-p44/42 MAPK (Thr202/Tyr204), phosphor-NF- $\mathrm{BB}$ p65 (Ser536), phosphor-S6k1 Ribosomal protein (S235/236) (D57.2.2E), $\beta$-actin, and HRP-conjugated anti-rabbit secondary $\mathrm{Ab}$ were purchased from Cell Signaling Technology.

SCFA treatment. Mice were given drinking water containing $1 \mathrm{gl}^{-1}$ metronidazole (Sigma-Aldrich, St. Louis, MO), $0.5 \mathrm{gl}^{-1}$ vancomycin (Hospira, Lake Forest, IL), $1 \mathrm{gl}^{-1}$ ampicillin (Sigma-Aldrich), and $1 \mathrm{gl}^{-1}$ kanamycin (Fisher Scientific, Waltham, MA) for 10 days, followed by SCFA feeding. Butyrate or acetate was added to drinking water with a final concentration of $300 \mathrm{~mm}$. Mice were sacrificed 21 days later for subsequent studies.
Isolation of IEC. After cleaning, small intestines were sliced into small pieces $(<0.5 \mathrm{~cm})$ and incubated with $5 \mathrm{~mm}$ EDTA in HBSS buffer containing $\% \mathrm{FBS}$ at $37^{\circ} \mathrm{C}$ for $40 \mathrm{~min}$. Cells were collected by passaging supernatant through a $100-\mu \mathrm{M}$ cell strainer (BD Falcon, Fremont, CA). After washing with PBS, IEC were separated from a 20/40\% Percoll interface (Amersham Pharmacia Biotech, Amersham, UK).

Epithelial cell culture. MSIE cells ${ }^{26}$ were maintained in RPMI 1640 medium with $5 \mathrm{U} \mathrm{ml}^{-1}$ murine IFN $\gamma$, ITS $\left(5 \mu \mathrm{g} \mathrm{ml}^{-1}\right.$ insulin, $5 \mu \mathrm{g} \mathrm{ml}^{-1}$ transferrin, and $5 \mathrm{ng} \mathrm{ml}^{-1}$ selenous acid), $100 \mathrm{U} \mathrm{ml}^{-1}$ penicillin/streptomycin, and $5 \% \mathrm{FBS}$ at $33^{\circ} \mathrm{C}$ and $5 \% \mathrm{CO}_{2}$. After reaching $80 \%$ confluence, cells were starved at $37^{\circ} \mathrm{C}$ for $16 \mathrm{~h}$ before 
subsequent experiments. HT-29 cells were cultured in complete McCoy's 5A Medium with $10 \% \mathrm{FBS}$ at $37^{\circ} \mathrm{C}$ and $5 \% \mathrm{CO}_{2}$.

siRNA transfection. siRNA transfection in MSIE cells was performed by using Lipofectamine RNAiMAX Transfection Reagent according to the manufacturer's instructions. Briefly, $3 \times 10^{5}$ MSIE cells were incubated with $50 \mathrm{~nm}$ siRNA and $10 \mu \mathrm{l}$ Lipofectamine RNAiMAX Transfection reagent in $1 \mathrm{ml}$ OPTI-MEM medium for $6 \mathrm{~h}$ at $33^{\circ} \mathrm{C}$, followed by normal growth medium for $40 \mathrm{~h}$ at $33^{\circ} \mathrm{C}$. MSIE cells were then starved for $6 \mathrm{~h}$ at $33^{\circ} \mathrm{C}$ before treatment. Transfection efficiency was determined at $40 \mathrm{~h}$ post transfection. The expression levels of RegIII $\gamma$ and $\beta$-defensins were determined at $48 \mathrm{~h}$ after administration with SCFA.

Flow cytometry. MSIE cells were treated with SCFA for $48 \mathrm{~h}$ then stained for Live/Dead dye and phospho-S6k1 (S235/236). Cells were sampled on a LSRII Fortessaflow cytometer (BD Biosciences, San Jose, $\mathrm{CA}$ ), and data analyzed by using FlowJo7.6 software (Tree Star, Ashland, OR).

Western blot. Total protein of cells was extracted and the concentration determined by a BCA Protein Assay kit. Four micrograms of protein was separated electrophoretically by NuPAGE Bis-Tris mini gels (Life Technologies, Carlsbad, CA, USA) and probed with phospho-mTOR, phospho-4EBP1, phospho-STAT3, phosphor-p44/ 42 MAPK, or phosphor-NF- $\kappa$ B p65 Abs overnight, followed by $1 \mathrm{~h}$ $\mathrm{HRP}$-conjugated anti-rabbit secondary Ab. Membranes were stripped and re-probed for actin as loading control. Protein $/ \beta$-actin relative expression was calculated using ImageJ (10.2) software.

Quantitative real-time PCR. Total RNA was extracted with TRIzol (Life Technologies) and quantified for cDNA synthesis. Quantitative real-time PCR reactions were performed by using SYBR Green Gene Expression Assays (Bio-Rad, Hercules, CA, USA). The primers are listed in Supplementary Table 1. All data were normalized to GAPDH mRNA expression.

Enteroid culture. The intestines were cut longitudinally, minced, and treated with $2 \mathrm{~mm}$ EDTA. The tissues were then treated with PBS containing $43.3 \mathrm{~mm}$ sucrose and $54.9 \mathrm{~mm}$ sorbitol, and filtered through a $70-\mu \mathrm{m}$ cell strainer. Supernatant was collected and centrifuged. The resulting pellet containing detached crypts was re-suspended in Matrigel (BD Bioscience, San Jose, CA) with $0.5 \mu \mathrm{g} \mathrm{ml}^{-1} \mathrm{rEGF}$ (R\&D Systems, Minneapolis, MN, 2028-EG), $1 \mu \mathrm{g} \mathrm{ml}^{-1}$ rNoggin (R\&D Systems, cat. no. 1967-NG/CF), $5 \mu \mathrm{g} \mathrm{ml}^{-1} \mathrm{rR}$-spondin (R\&D Systems, cat. no. 3474-RS), and $1 \mu \mathrm{g} \mathrm{ml}^{-1} \mathrm{rWnt} 3 \mathrm{a}$ (R\&D Systems, cat. no. 35036-WN/CF). In total, $50 \mu \mathrm{l}$ Matrigel with 500 crypts was plated, and advanced DMEM/F12 media (Invitrogen, Carlsbad, CA, cat. no. 12634-010) with $1 \times \mathrm{N} 2$ supplement (R\&D Systems, cat. no. AR009), and $1 \times$ B27 (Invitrogen, cat. no. 12587-010). Five days later, the enteroids were treated with $0.5 \mathrm{~mm}$ butyrate.

16S rRNA pyrosequencing analysis. Fecal bacterial DNA was isolated using a MoBio PowerFecal kit (MoBio, Carlsbad, CA, USA). The isolated DNA was amplified using universal V3-V4 16S rRNA V3-V4 region primers. Sequencing was performed with an Illumina MiSeq instrument. The raw sequencing reads were trimmed and filtered based on initial quality assessment using FASTQC. The reads were trimmed to 350 bases and filtered to exclude reads with low quality, two or more unknown characters, sequencing adapters. To identify the presence of known bacteria, the subsequences were analyzed using CLC Genomics Workbench 8.5 Microbial Genomics Module. Reference-based OTU picking was performed using the SILVA SSU v119 97\% database. Sequences present in more than one copy but not clustered to the database were then placed into de novo OTUs (97\% similarity) and aligned against the database with $80 \%$ similarity threshold using MUSCLE alignment.

Statistical analysis. Student's $t$ test in Prism 5.0 (Graphpad) was used to determine levels of significance for comparisons between samples.
Where appropriate, mean \pm s.e.m. is represented on graphs. ${ }^{\star} P<0.05$; ${ }^{* *} P<0.01$.

SUPPLEMENTARY MATERIAL is linked to the online version of the paper at http://www.nature.com/mi

\section{ACKNOWLEDGMENTS}

This work was supported by $\mathrm{NIH}$ grants DK098370, DK105585, and DK112436, and John Sealy Memorial Endowment Fund (to Y.C.). We appreciate Dr Linsey Yeager of The University of Texas Medical Branch for proofreading the manuscript.

\section{AUTHOR CONTRIBUTIONS}

Y.Z. and F.C. performed experiments, analyzed data, and wrote the manuscript. W.W., M.S., A.J.B., S.Y., Y.X., and X.H. performed part of experiments, analyzed data, and reviewed the manuscript. G.G., Y.X., and Y.F. performed and analyzed 16s rRNA pyrosequencing. T.D.E.-P., W.D., Q.Z., and Z.L. provided the reagents and revised the manuscript. Y.C. conceived the project, designed the experiments, and wrote the manuscript.

\section{DISCLOSURE}

The authors declared no conflict of interest.

(c) 2018 Society for Mucosal Immunology

\section{REFERENCES}

1. Bevins, C.L. \& Salzman, N.H. Paneth cells, antimicrobial peptides and maintenance of intestinal homeostasis. Nat. Rev. Microbiol. 9, 356-368 (2011).

2. Gallo, R.L. \& Hooper, L.V. Epithelial antimicrobial defence of the skin and intestine. Nat. Rev. Immunol. 12, 503-516 (2012).

3. Selsted, M.E. \& Ouellette, A.J. Mammalian defensins in the antimicrobial immune response. Nat. Immunol. 6, 551-557 (2005).

4. Cash, H.L., Whitham, C.V., Behrendt, C.L. \& Hooper, L.V. Symbiotic bacteria direct expression of an intestinal bactericidal lectin. Science 313, 1126-1130 (2006).

5. Hooper, L.V., Stappenbeck, T.S., Hong, C.V. \& Gordon, J.I. Angiogenins: a new class of microbicidal proteins involved in innate immunity. Nat. Immunol. 4, 269-273 (2003).

6. Brandl, K., Plitas, G., Schnabl, B., DeMatteo, R.P. \& Pamer, E.G. MyD88mediated signals induce the bactericidal lectin Reglll gamma and protect mice against intestinal Listeria monocytogenes infection. J. Exp. Med. 204, 1891-1900 (2007).

7. Vaishnava, S., Behrendt, C.L., Ismail, A.S., Eckmann, L. \& Hooper, L.V. Paneth cells directly sense gut commensals and maintain homeostasis at the intestinal host-microbial interface. Proc. Natl. Acad. Sci. USA 105, 20858-20863 (2008).

8. Sanos, S.L., Bui, V.L., Mortha, A., Oberle, K., Heners, C. \& Johner, C. RORgammat and commensal microflora are required for the differentiation of mucosal interleukin 22-producing NKp46 + cells. Nat. Immunol. 10, 8391 (2009).

9. Haghikia, A., Jörg, S., Duscha, A., Berg, J., Manzel, A. \& Waschbisch, A. Dietary fatty acids directly impact central nervous system autoimmunity via the small intestine. Immunity 43, 817-829 (2015).

10. Smith, P.M., Howitt, M.R., Panikov, N., Michaud, M., Gallini, C.A. \& Bohlooly-Y, M. The microbial metabolites, short-chain fatty acids, regulate colonic Treg cell homeostasis. Science 341, 569-573 (2013).

11. Cummings, J.H., Pomare, E.W., Branch, W.J., Naylor, C.P. \& Macfarlane, G.T. Short chain fatty acids in human large intestine, portal, hepatic and venous blood. Gut 28, 1221-1227 (1987).

12. Macia, L., Thorburn, A.N., Binge, L.C., Marino, E., Rogers, K.E. \& Maslowski, K.M. Microbial influences on epithelial integrity and immune function as a basis for inflammatory diseases. Immunol. Rev. 245, 164-176 (2012)

13. Kim, C.H., Park, J. \& Kim, M. Gut microbiota-derived short-chain fatty acids, T cells, and inflammation. Immune Netw. 14, 277-288 (2014). 
14. Natarajan, N. \& Pluznick, J.L. From microbe to man: the role of microbial short chain fatty acid metabolites in host cell biology. Am. J. Physiol. Cell Physiol. 307, C979-C985 (2014).

15. Brown, A.J., Goldsworthy, S.M., Barnes, A.A., Eilert, M.M., Tcheang, L. \& Daniels, D. The Orphan G protein-coupled receptors GPR41 and GPR43 are activated by propionate and other short chain carboxylic acids. J. Biol. Chem. 278, 11312-11319 (2003).

16. Alex, S., Lange, K., Amolo, T., Grinstead, J.S., Haakonsson, A.K. \& Szalowska, E. Short-chain fatty acids stimulate angiopoietin-like 4 synthesis in human colon adenocarcinoma cells by activating peroxisome proliferator-activated receptor gamma. Mol. Cell. Biol. 33, 1303-1316 (2013).

17. Chang, P.V., Hao, L., Offermanns, S. \& Medzhitov, R. The microbial metabolite butyrate regulates intestinal macrophage function via histone deacetylase inhibition. Proc. Natl. Acad. Sci. USA 111, 2247-2252 (2014).

18. Arpaia, N., Campbell, C., Fan, X., Dikiy, S., van der Veeken, J. \& deRoos, P. Metabolites produced by commensal bacteria promote peripheral regulatory T-cell generation. Nature 504, 451-455 (2013).

19. Furusawa, Y., Obata, Y., Fukuda, S., Endo, T.A., Nakato, G. \& Takahashi, D. Commensal microbe-derived butyrate induces the differentiation of colonic regulatory T cells. Nature 504, 446-450 (2013).

20. Hase, K., Eckmann, L., Leopard, J.D., Varki, N. \& Kagnoff, M.F. Cell differentiation is a key determinant of cathelicidin LL-37/human cationic antimicrobial protein 18 expression by human colon epithelium. Infect. Immun. 70, 953-963 (2002).

21. Schauber, J. et al. Expression of the cathelicidin LL-37 is modulated by short chain fatty acids in colonocytes: relevance of signalling pathways. Gut 52, 735-741 (2003).

22. Schauber, J. et al. Histone-deacetylase inhibitors induce the cathelicidin LL-37 in gastrointestinal cells. Mol. Immunol. 41, 847-854 (2004).

23. Steinmann, J., Halldorsson, S., Agerberth, B. \& Gudmundsson, G.H. Phenylbutyrate induces antimicrobial peptide expression. Antimicrob. Agents Chemother. 53, 5127-5133 (2009).

24. Kelly, C.J. et al. Crosstalk between microbiota-derived short-chain fatty acids and intestinal epithelial HIF augments tissue barrier function. Cell Host Microbe 17, 662-671 (2015).

25. Scheppach, W. Effects of short chain fatty acids on gut morphology and function. Gut 35, S35-S38 (1994).

26. Whitehead, R.H. \& Robinson, P.S. Establishment of conditionally immortalized epithelial cell lines from the intestinal tissue of adult normal and transgenic mice. Am. J. Physiol. Gastrointest. Liver Physiol. 296, G455G460 (2009).

27. Chi, H. Regulation and function of mTOR signalling in T cell fate decisions. Nat. Rev. Immunol. 12, 325-338 (2012).

28. Gurav, A. et al. Slc5a8, a Na ${ }^{+}$-coupled high-affinity transporter for shortchain fatty acids, is a conditional tumour suppressor in colon that protects against colitis and colon cancer under low-fibre dietary conditions. Biochem. J. 469, 267-278 (2015).

29. Choi, S.M. et al. Innate Stat3-mediated induction of the antimicrobial protein Reg3gamma is required for host defense against MRSA pneumonia. J. Exp. Med. 210, 551-561 (2013).

30. Li, A. et al. IL-22 up-regulates beta-Defensin-2 expression in human alveolar epithelium via STAT3 but not NF-kappaB signaling pathway. Inflammation 38, 1191-1200 (2015).

31. Murano, T. et al. Hes1 promotes the IL-22-mediated antimicrobial response by enhancing STAT3-dependent transcription in human intestinal epithelial cells. Biochem. Biophys. Res. Commun. 443, 840846 (2014).

32. Sovran, B. et al. IL-22-STAT3 pathway plays a key role in the maintenance of ileal homeostasis in mice lacking secreted mucus barrier. Inflamm. Bowel Dis. 21, 531-542 (2015).

33. Chen, $\mathrm{H}$. et al. Discovery of -alkylamino tethered niclosamide derivatives as potent and orally bioavailable anticancer agents. ACS Med. Chem. Lett. 4, 180-185 (2013).

34. Hooper, L.V. \& Macpherson, A.J. Immune adaptations that maintain homeostasis with the intestinal microbiota. Nat. Rev. Immunol. 10, 159169 (2010).

35. Lee, Y.K. \& Mazmanian, S.K. Has the microbiota played a critical role in the evolution of the adaptive immune system?. Science 330, 1768-1773 (2010).

36. Ley, R.E., Lozupone, C.A., Hamady, M., Knight, R. \& Gordon, J.I. Worlds within worlds: evolution of the vertebrate gut microbiota. Nat. Rev. Microbiol. 6, 776-788 (2008).

37. Zeng, $X$. et al. Induction of porcine host defense peptide gene expression by short-chain fatty acids and their analogs. PLOS ONE 8, e72922 (2013).

38. Ganapathy, V., Thangaraju, M., Prasad, P.D., Martin, P.M. \& Singh, N. Transporters and receptors for short-chain fatty acids as the molecular link between colonic bacteria and the host. Curr. Opin. Pharmacol. 13, 869874 (2013).

39. McKenzie, C.I., Mackay, C.R. \& Macia, L. GPR43 - a prototypic metabolite sensor linking metabolic and inflammatory diseases. Trends Endocrinol. Metab. 26, 511-512 (2015).

40. Maslowski, K.M. et al. Regulation of inflammatory responses by gut microbiota and chemoattractant receptor GPR43. Nature 461, 1282-1286 (2009).

41. Macia, L. et al. Metabolite-sensing receptors GPR43 and GPR109A facilitate dietary fibre-induced gut homeostasis through regulation of the inflammasome. Nat. Commun. 6, 6734 (2015).

42. Schilderink, R. et al. The SCFA butyrate stimulates the epithelial production of retinoic acid via inhibition of epithelial HDAC. Am. J. Physiol. Gastrointest. Liver Physiol. 310, G1138-G1146 (2016).

43. Laplante, M. \& Sabatini, D.M. mTOR signaling in growth control and disease. Cell 149, 274-293 (2012).

44. Haidinger, M. et al. A versatile role of mammalian target of rapamycin in human dendritic cell function and differentiation. J. Immunol. 185, 3919-3931 (2010).

45. Ernst, M., Thiem, S., Nguyen, P.M., Eissmann, M. \& Putoczki, T.L. Epithelial gp130/Stat3 functions: an intestinal signaling node in health and disease. Semin. Immunol. 26, 29-37 (2014).

46. Behnsen, J. et al. The cytokine IL-22 promotes pathogen colonization by suppressing related commensal bacteria. Immunity 40, 262-273 (2014).

47. Jiminez, J.A., Uwiera, T.C., Abbott, D.W., Uwiera, R.R.E. \& Inglis, G.D. Butyrate supplementation at high concentrations alters enteric bacterial communities and reduces intestinal inflammation in mice infected with Citrobacter rodentium. mSphere 2, e00234-17 (2017).

48. Namkung, H., Yu, H., Gong, J. \& Leeson, S. Antimicrobial activity of butyrate glycerides toward Salmonella typhimurium and Clostridium perfringens. Poult. Sci. 90, 2217-2222 (2011).

49. Macfarlane, S. \& Macfarlane, G.T. Regulation of short-chain fatty acid production. Proc. Nutr. Soc. 62, 67-72 (2003).

50. Wang, Y. et al. The first synthetic agonists of FFA2: discovery and SAR of phenylacetamides as allosteric modulators. Bioorg. Med. Chem. Lett. 20, 493-498 (2010). 